Revista Ingeniería y Región. 2016;16(2): 73-84

http://dx.doi.org/10.25054/22161325.1301

\title{
Evaluación del enriquecimiento proteico de residuos de papa y yuca con (Paecilomyces variotti)
}

\section{Evaluation of protein enrichment of waste potato and cassava with (Paecilomyces variotti)}

\author{
Juan Camilo Oviedo L ${ }^{1}$, Diego León Zapata R ${ }^{2}$, Lucas García E ${ }^{3}$, Natalia Echeverri $\mathrm{S}^{4}$ \\ y David Echeverri $\mathrm{S}^{5}$
}

\begin{abstract}
Resumen
Los problemas de suministro de proteína hacen necesaria la búsqueda de alternativas distintas a las fuentes tradicionales. La proteína microbiana, celular o unicelular (PUC), es una opción favorable. Una de las ventajas de la PUC, es que emplea como sustratos residuos de actividades industriales y desechos de poscosecha, como residuos agroindustriales (RA). Dentro los RA, se encuentran los desechos de papa y yuca, los cuales no reciben actualmente un tratamiento para darles valor agregado. Una forma de valorizar estos residuos es a través del enriquecimiento proteico producto de la fermentación en estado sólido (FES). En este trabajo, empleando residuos de papa y yuca como fuente de carbono y energía, evaluamos la adición de dos fuentes de nitrógeno: sulfato de amonio $(10 \mathrm{~g} / \mathrm{L})$ y peptona $(10 \mathrm{~g} / \mathrm{L})$ y dos niveles de humedad $(10$ y $30 \%)$ a través de un diseño de experimentos factorial $2^{2}$, con una duración de 24 días. La proteína fue medida por el método de Biuret, previa separación de la proteína del sustrato. Nuestro análisis estadístico indica que los efectos combinados fueron mejores que los simples: para la papa el más alto enriquecimiento proteico fue de $166,29 \%$, obtenido con la combinación de humedad del $30 \%$ y sulfato de amonio como fuente de nitrógeno. Para la yuca el más alto enriquecimiento proteico fue de $171,05 \%$, obtenido a un $10 \%$ de humedad y con peptona como fuente de nitrógeno.
\end{abstract}

Palabras clave: proteína unicelular (PUC); residuos agroindustriales; sustratos amiláceos; fermentación en estado Sólido (FES); Paecilomyces variotti.

\footnotetext{
Abstract

Problems in the protein supply call for alternatives to traditional sources. In this context, cell or single-cell microbial protein (SCP) is an appealing option. One of the advantages of SCP, is that use of industrial and post-harvest wastes, such as agro-industrial wastes (AWs). Within AWs are waste potato and cassava, which currently do not receive any treatment to add them value. A way

Ph.D. Profesor Titular, Docente Fac. Ing. Agroindustrial. Universidad Pontificia Bolivariana. juan.oviedo@upb.edu.co Mg. Profesor Asistente, Docente Fac. Ing. Industrial. Universidad Pontificia Bolivariana. diego.zapata@upb.edu.co Ingeniero Agroindustrial, Universidad Pontificia Bolivariana. lucasgarciaestrada@gmail.com

Ingeniero Agroindustrial, Universidad Pontificia Bolivariana. vichieche@yahoo.com

Ingeniero Agroindustrial, Universidad Pontificia Bolivariana. natyeche28@hotmail.com
} 
of doing so is via protein enrichment from solid-state fermentation (SSF). In this work, we used potato and cassava residues as a source of carbon and energy, and assessed the effect of adding two types of nitrogen sources: ammonium sulfate $(10 \mathrm{~g} / \mathrm{L})$ and peptone $(10 \mathrm{~g} / \mathrm{L})$ and two levels of humidity (10 and 30\%) through a $2^{2}$ factorial design of experiments carried out for 24 days. The protein level was measured with the Biuret method after removal of the substrate's protein. Our statistical analysis indicates that the combined effects were better than the simple ones: for potato residues, the highest protein enrichment was $166,29 \%$, obtained from a combination of a humidity level of $30 \%$ and ammonium sulfate as nitrogen source. For cassava residues, the highest protein enrichment was $171.05 \%$, obtained from a combination of $10 \%$ moisture and peptone as nitrogen source peptone.

Keywords: single-cell protein (scp); agro-industrial waste; Starch substrates; solid-state fermentation (ssf); paecilomyces variotti.

\section{Introducción}

La industria de alimentos se encuentra en un momento coyuntural para abastecer de alimentos tanto a los humanos como a los animales, debido en algunos casos a la escasez y en otros a los costos de producción (Pereira, et al., 2014; Chacón, 2004). Dentro de los diferentes componentes alimenticios, las proteínas son los más escasos y costosos, sea su origen animal, vegetal o microbiano (Badui, 2006). Las proteínas de origen animal, especialmente las procedentes del ganado, son las más costosas y lentas de producir: en ganadería, cada siete kilos de las proteínas de los concentrados se convierten en un kilo de proteínas animales (Primo, 1998). De otro lado, la industria de alimentos para animales se encuentra constantemente en búsqueda de nuevos productos que puedan obtenerse en cantidades suficientes y en la mayor brevedad posible para la formulación de los concentrados, sobre todo a base de proteína (Fontes, etal., 2015); (Pereira, et al., 2014).

Una de las alternativas de producción proteica son las proteínas de origen microbiano o proteínas unicelulares (PUC) o SCP (por sus siglas en inglés, single-cell protein). Son proteínas producidas por procesos de fermentación controlada por cepas puras o mezcladas de hongos, bacterias, y algas unicelulares y filamentosas (Wang, et al., 2012); (Tacon, 1989). Las PUC pueden potencialmente reemplazar algunas de las fuentes tradicionales de proteína (soya, harina de pescado, suero descremado de leche) en piensos para el consumo animal, además de ser una alternativa para solventar el problema de la cada vez más limitada disponibilidad e ingesta de proteína (Phetteplace, et al., 2003); (Hu, etal., 2013).

Entre las décadas de los 60s y 70s, los bioprocesos para obtener PUC empleaban como materia prima subproductos de la industria de los hidrocarburos y el petróleo. Sin embargo, hoy estos sustratos son económicamente inviables, debido a los incrementos del petróleo y sus derivados (Biocyclopedia, 2012); (Ukaegbu-Obi, 2016), por lo que en los últimos años se ha comenzado a emplear como sustratos desechos o residuos de poscosecha, ya que éstos presentan una fuente apropiada de alimento para los microorganismos y sus costos son inferiores con respecto a los de los hidrocarburos. Adicionalmente, el hecho de ser residuos atenúa la problemática medio ambiental, pues se le confiere valor agregado a dichos desechos (Nasseri, et al., 2011); (Suman, et al., 2015). Entre este tipo de residuos, se destacan los de la producción de papa y yuca. La papa y la yuca son dos tubérculos cultivados extensamente en el territorio Colombiano: en el año 2014 se produjeron 2'800.000 toneladas de papa y 2'200.000 toneladas de yuca (FINAGRO, 2014). Se estima que los residuos de poscosecha que generan estos dos tubérculos son aproximadamente del 20\%. Ese gran volumen de desechos es un problema medio ambiental sin regulación en la actualidad (FINAGRO, 2014).

El Paelomyces variotti es hongo filamentoso, con la misma clasificación ambiental y clínica de las especies Aspergillus spp, los cuales han sido empleados para la producción de proteína para elaborar alimentos para animales (Azam, et al., 2014); (Ardestani \& Alishahi, 2015); (Suman, et al., 2015); particularmente el Paelomyces variotti ha sido reportado como productor de PUC biotransformando diversos sustratos como melazas, material lignocelulósico y residuos procedentes de las industrias del papel, textily del petróleo (Almeida, et al., 1995); (Pereira, et al., 2010); (Steen, 2014).

En este orden de ideas, este trabajo se llevó a cabo con el objetivo de aprovechar los desechos de papa y 
yuca a través de la fermentación en estado sólido (FES) empleando el hongo filamentoso Paecilomyces variotti. Este proceso pretende enriquecer de proteína microbiana tanto la papa como la yuca, y ésta a su vez Paecilomyces variotti podría ser empleado como alimento animal en otros estudios (Madeira, et al., 2011); (Aggelopoulos, et al., 2014).

\section{Materiales y métodos}

\subsection{Selección y cultivo del microorganismo}

El hongo seleccionado para esta investigación luego de una preselección bibliográfica fue el hongo filamentoso Paecilomyces variotti. La cepa fue obtenida en el laboratorio de Microbiología de la Universidad Pontificia Bolivariana. Se cultivó en agar Sabouraud Merck ${ }^{\circledR}$, preparado según las especificaciones del fabricante (Merck, 2010).

\subsection{Preparación del inóculo}

El inóculo del Paecilomyces variotti se preparó en medio líquido, de acuerdo con los requerimientos nutricionales del hongo. Se empleó una concentración aproximada de $1 \times 10^{7}$ esporas $/ \mathrm{mL}$. La composición del medio de cultivo fue: $5 \mathrm{~g}$ de extracto de carne $/ 1,5 \mathrm{~g}$ de peptona universal/1 y $40 \mathrm{~g}$ de glucosa/ 1. Todos los componentes se diluyeron en agua destilada y se esterilizaron 15 minutos a 121 psi. Una vez el anterior medio llegaba a temperatura ambiente, se llevaba a una cámara de flujo laminar y sobre él se vertían las esporas del Paecilomyces variotti obtenidas en el apartado 2.1, lavadas con agua destilada y esterilizada. El anterior montaje era llevado a un agitador orbital a $150 \mathrm{rpm}$ por un período de 72 horas.

\subsection{Obtención y pretratamiento del sustrato}

La papa y la yuca fueron obtenidas en la plaza de mercado Central Mayorista de Abastos de Antioquia. Se seleccionó cualquier material vegetal descartado por los comerciantes, excepto cuando tuviera alguna enfermedad visible. El sustrato se sometió a una reducción de tamaño en trozos circulares, y se llevó a un horno de convección forzada por 48 horas a $70^{\circ} \mathrm{C}$ para retirarle el contenido de humedad. Una vez deshidratado, fue almacenado en bolsas resellables por no más de 30 días, para evitar contaminación con microorganismos indeseables.

\subsection{Caracterización del sustrato}

Se llevó a cabo una caracterización de los sustratos por análisis bromatológico (humedad, determinación de cenizas, determinación de grasa, determinación de fibra cruda y determinación de proteína), empleando métodos oficiales de análisis de alimentos, basados en la norma AOAC 1997 para determinar las características iniciales del sustrato seleccionado.

\subsection{Adaptación del microrganismo al sustrato}

Con el objetivo de conocer cómo se adapta el hongo a la papa y a la yuca como fuente de carbono y energía, se evaluó el crecimiento cualitativo del Paecilomyces variotti, cultivado en diferentes contenidos de humedad: se evaluaron porcentajes de $10 \%, 30 \%, 50 \%$ y $80 \%$. Se evaluó la humedad porque es una de las variables más importantes en la FES (Padey, et al., 2008).

\subsection{Medición de la cinética de crecimiento}

Una vez conocida la humedad a la que se adaptó mejor el hongo, se evaluó el tiempo que éste emplea para invadir la papa y la yuca. Para ello, se tomaron 24 cajas de Petri esterilizadas en donde se encontraba el medio de cultivo (residuo amiláceo y ajuste de humedad con agua de grifo esterilizada); con la biomasa producida en el ítem 2.2. Una vez inoculadas las 24 cajas de Petri, se llevaron a una incubadora a $25^{\circ} \mathrm{C}$ y en condiciones de oscuridad. Cada tres días, se tomaba una caja de Petri por cada tipo de residuo (yuca y papa), y se llevaban a un congelador a temperatura de $-22{ }^{\circ} \mathrm{C}$ hasta completar las 24 cajas en congelación, donde se determinó la proteína previa extracción del sustrato. Este proceso se hizo por triplicado.

\subsection{Extracción de proteína y su medición mediante el método de Biuret}

Para la medición de la proteína, se sustrajo la proteína del sustrato. La extracción de proteína se realizó mediante un procedimiento ajustado al propuesto Rezende et al (2002) donde la muestra se sumergía en una solución extractora de Acetato de sodio $50 \mathrm{mM}$ en una relación 1:5 muestra: solución. Paso seguido, hay un proceso de agitación orbital de por lo menos 1 hora; finalmente se llevó a cabo una separación de la proteína extraída por centrifugación en frío $\left(\mathrm{a}^{\circ} \mathrm{C}\right)$ por 15 minutos a $9000 \mathrm{rpm}$. Para la medición de proteína, la metodología fue el método de Biuret, que es una reacción coloreada (violeta) debida a la formación de un 
complejo de $\mathrm{Cu}^{2+}$ en medio alcalino en compuestos que poseen más de un grupo CO-NH (Quesada, 2007).

\subsection{Diseño de experimentos para evaluar el enriquecimiento proteico}

Con el objeto de evaluar la adición de fuentes de nitrógeno orgánico (peptona, $10 \mathrm{~g} / \mathrm{L}$ ) e inorgánico (sulfato de amonio, $10 \mathrm{~g} / \mathrm{L})$ y el contenido de humedad $(10 \% \mathrm{y}$ $30 \%$ ), se llevó a cabo un diseño de experimentos factorial $2^{2}$, donde la variable respuesta fue el enriquecimiento proteico. En la tabla 1, aparece la matriz de diseño de experimentos para la papa y la yuca. Para cada uno de los tubérculos, se realizaron 3 réplicas por diseño.

El análisis descriptivo de datos y el análisis de varianza ANOVA para el diseño factorial 22, se realizó en el complemento de MS Excel® de Análisis de Datos, con las funciones de Estadística Descriptiva y Análisis de Varianza de dos Factores con Varias Muestras por Grupo.

\section{Resultados y discusión}

\subsection{Selección del microorganismo y caracterización del sustrato}

El hongo Paecilomyces variotti fue seleccionado para este trabajo de investigación por su carácter comestible de alto valor nutritivo y proteico, empleado para alimentar animales. El hongo tiene una tasa de crecimiento satisfactoria y ha sido explotado industrialmente para mejorar el sustrato fermentado como complemento alimenticio para animales (Ibrahim, 2009). Los resultados de la Tabla 2 muestran La caracterización de la papa y la yuca.

Con respecto a los datos obtenidos en la tabla anterior, la humedad obtenida experimentalmente en la yuca fue de $63.77 \%$ y en la papa de $80.04 \%$. Estos valores son similares a los reportados por el Ministerio de Agri- cultura en 2014, donde se mencionan un rango de humedad para la yuca entre un 60 a $65 \%$ de humedad y otro para la papa de 63 a 87\% (FINAGRO, 2014).

Los porcentajes de grasa obtenidos en el laboratorio para la yuca y la papa son relativamente bajos comparados con los de otros residuos agroindustriales como la tusa de maíz, cuyo porcentaje de grasa es de $10.87 \%$ (Madeira, et al., 2011) (Aggelopoulos, et al., 2014). Debe tenerse en cuenta que los tubérculos no son una fuente importante de lípidos, pues para la papa fueron de $0.4 \%$ y para la yuca de $0.8 \%$ respectivamente. El porcentaje de lípidos o grasa cruda en la papa y en la yuca en fresco es muy bajo. Se ha reportado que no tienen importancia desde un punto de vista cuantitativo $0.3 \%$ y $0.5 \%$ según la literatura (Zapata \& Navas, 2006), valores muy cercanos a los medidos en este trabajo.

El contenido de cenizas de un producto es el residuo resultante después de su incineración en condiciones determinadas. Los resultados están acordes con la información reportada en FINAGOR (2014) el análisis realizado arrojó datos para el porcentaje de cenizas en la yuca de $0.84 \%$, mientras que para la papa se obtuvo un valor de $1.3 \%$, valores que muestran diferencias en el contenido de cenizas entre los datos teóricos y experimentales de $33 \%$ para la papa y de $26 \%$ para la yuca. Un aumento en la cantidad de cenizas puede estar relacionado con un aumento en el contenido de minerales en los almidones de la yuca y la papa, además se reporta que el contenido de fósforo y de algunos minerales en papa y yuca influye en el contenido final de las cenizas (Hoover, 2002).

El nivel de fibra tanto en la yuca como en la papa presentan pequeñas variaciones según la variedad y edad, normalmente el valor no pasa de $1.5 \%$ en la yuca y de $3.5 \%$ en la papa (Madeira, et al., 2011); (Aggelopoulos, et al., 2014). Durante la caracterización de ambos sustratos se evaluó el porcentaje de fibra, dando resultados para la papa de $1.2 \%$ y para la yuca de $0.71 \%$.

Tabla 1. Matriz de experimentos para la PUC con sustratos de yuca y papa

\begin{tabular}{lccc}
\hline Ensayo & Humedad (\%) & Fuente de Nitrógeno & Variable Respuesta \\
\hline 1 & 10 & Peptona & \\
2 & 10 & $\left(\mathrm{NH}_{4}\right)_{2} \mathrm{SO}_{4}$ & \% Incremento de Proteína \\
3 & 30 & Peptona & \\
4 & 30 & $\left(\mathrm{NH}_{4}\right)_{2} \mathrm{SO}_{4}$ & \\
\hline
\end{tabular}


Tabla 2. Caracterización físico-química de la papa y la yuca en base húmeda.

\begin{tabular}{l|cc|cc}
\hline \multicolumn{2}{c}{ Yuca } & \multicolumn{2}{c}{ Papa } \\
\hline $\begin{array}{c}\text { Variable } \\
(\%)\end{array}$ & $\begin{array}{c}\text { Media } \\
\text { Muestral }\end{array}$ & $\begin{array}{c}\text { Desv. } \\
\text { Típica }\end{array}$ & $\begin{array}{c}\text { Media } \\
\text { Muestral }\end{array}$ & $\begin{array}{c}\text { Desv. } \\
\text { Típica }\end{array}$ \\
\hline Humedad & 63,773 & 1,638 & 79,893 & 9,777 \\
Cenizas & 0,845 & 0,063 & 1,307 & 0,713 \\
Grasa & 0,844 & 0,172 & 0,435 & 0,149 \\
Fibra & 0,713 & 0,004 & 1,199 & 0,030 \\
Proteína & 1,232 & 0,317 & 1,299 & 0,315 \\
\hline
\end{tabular}

\subsection{Adaptación y cinética del Paecilomyces variotti en la papa y a la yuca}

En la figura 1 se muestra el crecimiento en el tiempo del Paelomyces variotti en la papa y en la yuca.

El crecimiento del Paelomyces variotti tanto en la papa como en la yuca muestra un comportamiento logístico. Dentro de los modelos matemáticos de crecimiento para FES, el logístico es uno de los más empleados. El modelo logístico ha sido empleado para crecimiento de poblaciones, propagación de enfermedades y cuantificación de biomasa en bioprocesos en sistemas líquidos (sumergidos) y sólidos (Quiñonez \& Lecompte, 2007); (Orlandoni, 1997); (Peleg, et al, 2007); (Oviedo, et al, 2014). El perfil de crecimiento logístico es ampliamente empleado en FES, debido a que es un modelo simple, que tiene una ecuación que da una aproximación adecuada de toda la curva de crecimiento, incluyendo la fase de latencia y cese de crecimiento en las últimas etapas de la fermentación (Mitchell, et al., 2004). De acuerdo con la figura 1 a los 27 días del ensayo, la concentración obtenida de proteína para la papa fue de $5.359 \pm 0.339 \mathrm{mg} / \mathrm{ml} \mathrm{y}$ de $4.846 \pm 0.288 \mathrm{mg} / \mathrm{ml}$ para la yuca. Sin embargo, a los 21 días se llega a un máximo crecimiento representativo para ambos tubérculos, con unas concentraciones de proteína de $5.218 \pm 0.030 \mathrm{mg} / \mathrm{ml}$ para la papa y de $4.833 \pm 0.011 \mathrm{mg} / \mathrm{ml}$ para la yuca. A partir de este punto, se presenta un crecimiento muy leve, con tendencia a estabilizarse. Con el resultado descrito en la figura 1, se determina que un tiempo prudente para llevar a cabo el diseño de experimentos es de 24 días, periodo en el cual se alcanza un umbral estable para el crecimiento proteico en ambos sustratos amiláceos.

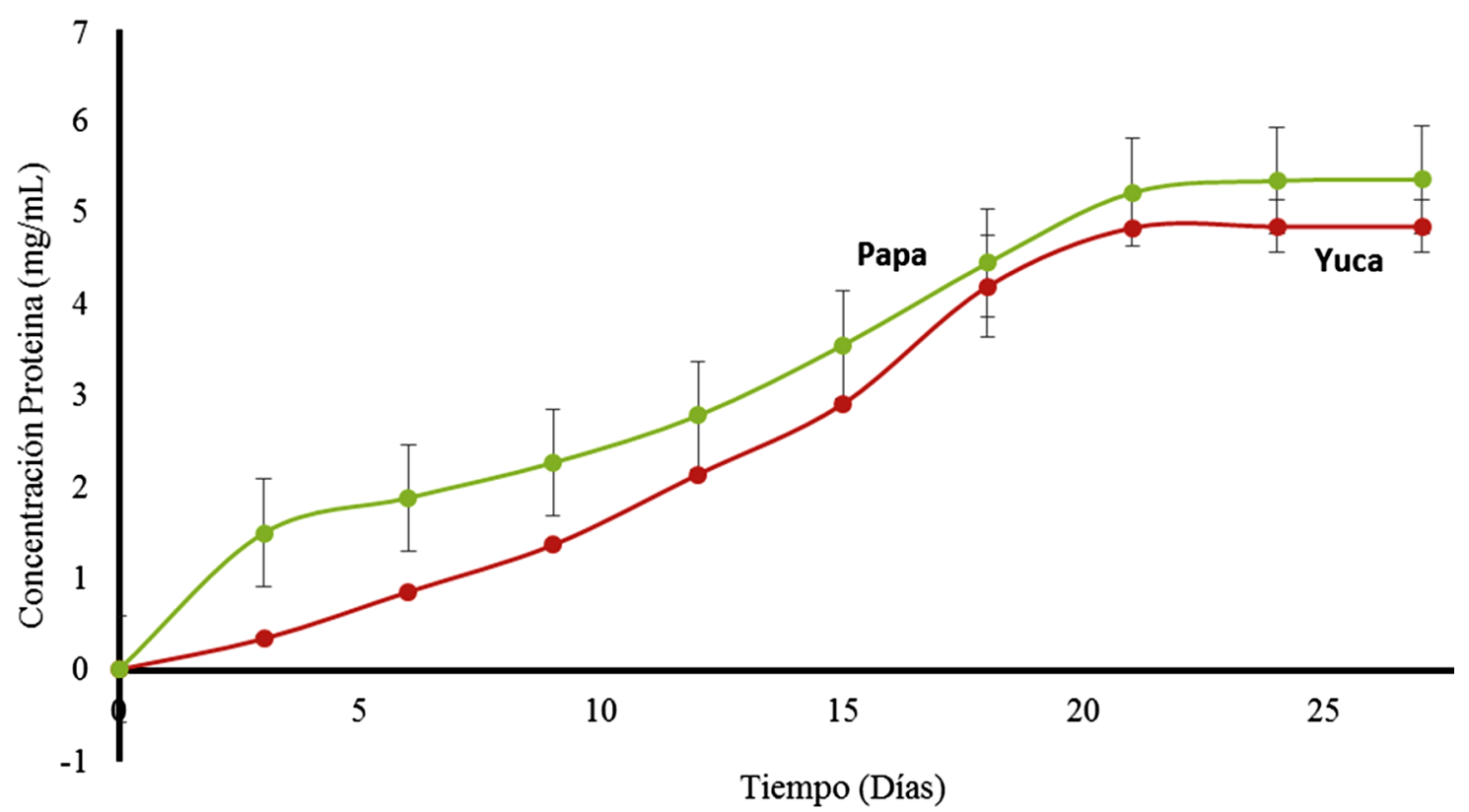

Figura 1. Cinética del Paelomyces variotti en papa y yuca 


\subsection{Resultados del diseño de experimentos}

Los resultados del diseño de experimentos, se muestran en las tablas 3 y 4 para los dos tubérculos estudiados.

Los resultados presentados en las Tablas 3 y 4 , muestran que, para el caso de la papa, el mayor incremento de proteína fue alcanzado al combinar 30\% de humedad con sulfato de amonio, con un valor de 166,29 \pm 75,18 . Para el caso de la yuca, la combinación que mostró el mejor incremento de proteína fue $10 \%$ de humedad con peptona, arrojando un valor de $171,05 \pm$ 92,96 . Sin embargo, se realizó un análisis estadístico ANOVA para encontrar diferencias significativas. En la Tabla 5 se muestra la Anova para el estudio realizado en la papa.
Los resultados del análisis de varianza del diseño experimental $2^{2}$ con cuatro observaciones por grupo determinan el aporte de cada uno de los factores (humedad y fuente de nitrógeno) a la variabilidad del modelo (\% Enriquecimiento proteico). Las hipótesis que se contrastan son:

Ho: $\quad$ Efecto de la humedad $=0$

Ho: Efecto de la fuente de nitrógeno $=0$

Ho: Efecto de la interacción (humedad x fuente de nitrógeno) $=0$

En cuanto al análisis de varianza para la papa mostrado en la Tabla 3, el valor estadístico F-Fisher y la columna para el estadístico de prueba Fo, con un nivel de significancia de 0,05 , se aceptan las tres hipótesis, es

Tabla 3. Resultados del diseño de experimentos para la papa

\begin{tabular}{c|c|c|c}
\hline $\begin{array}{c}\text { Porcentaje } \\
\text { Humedad }\end{array}$ & $\begin{array}{c}\text { Fuente de } \\
\text { Nitrógeno }\end{array}$ & $\begin{array}{c}\text { Porcentaje } \\
\text { Incremento Proteína }\end{array}$ & $\begin{array}{c}\text { Desviación } \\
\text { Típica }\end{array}$ \\
\hline 10 & Peptona & 116,72 & 75,24 \\
\hline 10 & $\left(\mathrm{NH}_{4}\right)_{2} \mathrm{SO}_{4}$ & 135,35 & 107,99 \\
\hline 30 & $\mathrm{Peptona}_{\mathrm{A}}$ & 111,31 & 37,26 \\
\hline 30 & $\left(\mathrm{NH}_{4}\right)_{2} \mathrm{SO}_{4}$ & 166,29 & 75,18 \\
\hline
\end{tabular}

Tabla 4. Resultados del diseño de experimentos para la yuca.

\begin{tabular}{c|c|c|c}
\hline $\begin{array}{c}\text { Porcentaje } \\
\text { Humedad }\end{array}$ & $\begin{array}{c}\text { Fuente de } \\
\text { Nitrógeno }\end{array}$ & $\begin{array}{c}\text { Porcentaje } \\
\text { Incremento Proteína }\end{array}$ & $\begin{array}{c}\text { Desviación } \\
\text { Típica }\end{array}$ \\
\hline 10 & Peptona & 171,05 & 92,96 \\
\hline 10 & $\left(\mathrm{NH}_{4}\right)_{2} \mathrm{SO}_{4}$ & 110,57 & 49,61 \\
\hline 30 & Peptona & 145,46 & 69,71 \\
\hline 30 & $\left(\mathrm{NH}_{4}\right)_{2} \mathrm{SO}_{4}$ & 153,93 & 104,93 \\
\hline
\end{tabular}

Tabla 5. Anova para los ensayos realizados en papa.

\begin{tabular}{lccccc}
\hline $\begin{array}{c}\text { Origen de las } \\
\text { variaciones }\end{array}$ & $\begin{array}{c}\text { Suma de } \\
\text { cuadrados }\end{array}$ & $\begin{array}{c}\text { Grados de } \\
\text { libertad }\end{array}$ & $\begin{array}{c}\text { Promedio } \\
\text { cuadrados }\end{array}$ & Fo & F \\
\hline Fuente de & 38,087 & 1 & 38,087 & 0,638 & 4,747 \\
Nitrógeno & 12,160 & 1 & 12,160 & 0,204 & 4,747 \\
Humedad & 6,460 & 1 & 6,460 & 0,108 & 4,747 \\
Interacción & 716,727 & 12 & 59,727 & & \\
Error & 773,435 & 15 & & & \\
\hline Total & & & & & \\
\hline
\end{tabular}


decir, que para cada efecto, $\mathrm{F}>\mathrm{Fo}$, concluyéndose así, que no existe evidencia estadística para argumentar el aporte de los factores y sus niveles al enriquecimiento proteico. Ahora bien, al observar los estadísticos de prueba Fo, el valor correspondiente a la humedad, se aprecia como el efecto más importante del modelo. El análisis de varianza para la yuca se realizó se encuentra consignado en la tabla 6.

El análisis de varianza para la yuca en la Tabla 4, y el valor estadístico F-Fisher y la columna para el estadístico de prueba Fo en la tabla 6, con un nivel de significancia de 0,05 , muestran que se aceptan las tres hipótesis, es decir, que para cada efecto, $\mathrm{F}>\mathrm{Fo}$, concluyéndose así nuevamente, que no existe evidencia estadística para argumentar el aporte de los factores y sus niveles al enriquecimiento proteico. Sin embargo, al observar los estadísticos de prueba Fo, el valor correspondiente a la interacción de los factores (humedad $x$ fuente de nitrógeno), se aprecia como el efecto más importante del modelo.

Ahora bien, al observar los estadísticos de prueba Fo, el valor correspondiente a la Humedad, se aprecia como el efecto más importante del modelo. Dichos efectos para la papa, se muestra en la figura 2 .

Los efectos empíricos para los factores y su interacción para el enriquecimiento de la papa, se muestran en la Figura 2, donde se evidencia un mayor efecto en la interacción de los factores cuando la Humedad está en su nivel alto $(30 \%)$ y cuando la fuente de nitrógeno es sulfato de amonio. Los efectos mayores se observan cuando la fuente de nitrógeno es sulfato de amonio en los dos niveles de la humedad. Para mostrar los efectos en la yuca, se muestra la Figura 3.

La Figura 3, indica que hay un mayor efecto en la interacción de los factores cuando la Humedad está en su nivel bajo (10\%) y la fuente de nitrógeno es peptona.

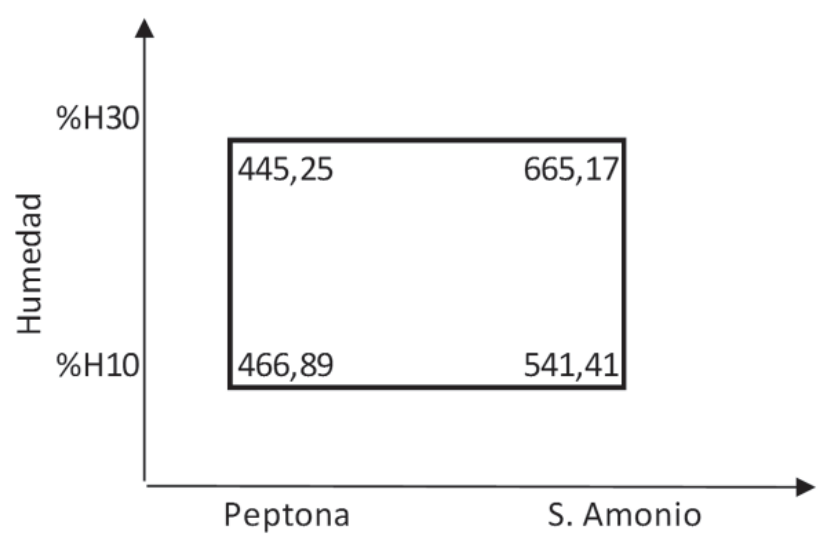

Figura 2. Efectos de los factores para la papa.

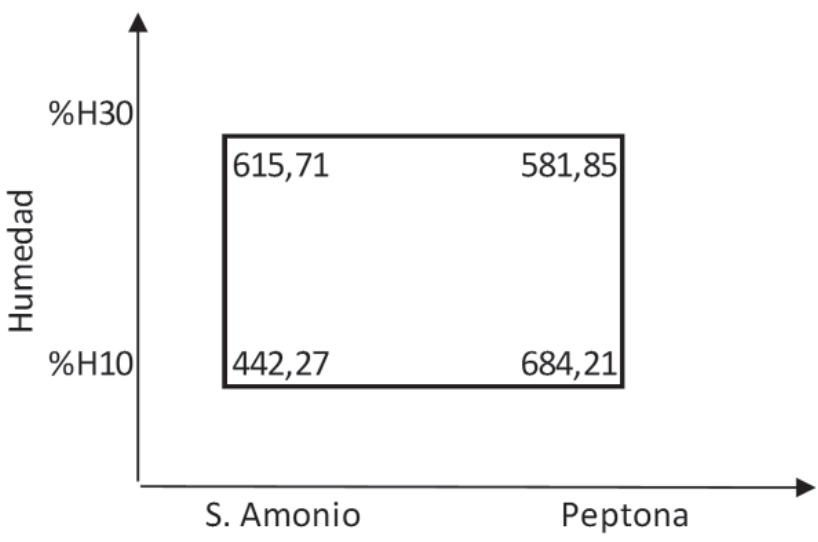

Figura 3. Efectos de los factores para la yuca.

De acuerdo a los resultados estadísticos obtenidos, la humedad se muestra como un factor fundamental para el crecimiento, tanto en la papa como la yuca; el contenido de humedad en FES es esencial para el metabolismo fúngico, debido a permite una buena difusión de gases y solutos en la célula, mantenimiento del funcionamiento del aparato enzimático y facili-

Tabla 6. Anjova para los ensayos realizados en yuca.

\begin{tabular}{lccccc}
\hline $\begin{array}{c}\text { Origen de las } \\
\text { variaciones }\end{array}$ & $\begin{array}{c}\text { Suma de } \\
\text { cuadrados }\end{array}$ & $\begin{array}{c}\text { Grados de } \\
\text { libertad }\end{array}$ & $\begin{array}{c}\text { Promedio } \\
\text { cuadrados }\end{array}$ & Fo & F \\
\hline Fuente de & 23,106 & 1 & 23,106 & 0,40, & 4,7472 \\
Nitrógeno & 2,696 & 1 & 2,696 & 0,0407 & 4,7472 \\
Humedad & 40,590 & 1 & 40,590 & 0,705 & 4,7472 \\
Interacción & 690,870 & 12 & 57,573 & & \\
Error & 757,261 & 15 & & & \\
\hline Total & & & & & \\
\hline
\end{tabular}


tando la permeabilidad, transporte de nutrientes y eliminación de desechos entre la célula y el ambiente. Al parecer los contenidos de $10 \%$ y $30 \%$ de agua son suficientes para el funcionamiento celular, sobre todo a escala intracelular donde se llevan a cabo todos los procesos metabólicos del Paecilomyces variotti. Para el crecimiento de hongos filamentos en sustratos sólidos, se ha considerado un $30 \%$ de humedad en residuos agroindustriales como lo muestra el trabajo de Aguilar-Navarro et al (2014) durante el proceso de este trabajo, fue más fácil realizar un ajuste de humead al 30\%, debido a que dicho contenido de agua se obtenida más rápido y era menos dispendioso.

En lo referente a las fuente de nitrógeno, los hongos filamentosos y mesofilos como Paecilomyces variotti, Aspergillus niger, Trichoderma reesei entre otros, son de fácil adaptación a diferentes condiciones ambientales donde por lo general, no hay altas concentraciones en las fuentes de nitrógeno; algunos estudios muestran que los residuos amiláceos, contienen pequeñas cantidades de nitrógeno como es el caso de Kurcz et al (2016) quienes señalan que los residuos de la papa contienen concentraciones de nitrógeno y han sido empleados para la producir PUC. La mayoría de los microrganismo aerobios como el Paecilomyces variotti tienen la capacidad de emplear tanto el nitrógeno orgánico e inorgánico; la decisión de tomar una fuente $u$ otra pasaría por el aspecto económico; las fuentes de nitrógeno como peptonas y extractos de levadura, son materias primas muy costosas y la literatura reporta estudios para que sean reemplazadas por residuos ricos de nitrógeno o fuentes más económicas (Altaf, et al., 2006), en este caso sulfato de amonio.

Como se mencionó anteriormente, ya se han empleado residuos amiláceos para la producción de PUC, sin embargo es importante mencionar que el Paecilomyces spp ha sido aislado naturalmente de sustratos amiláceos, como es el caso del arroz, donde el hongo realizó procesos de biodegradación del almidón (Sanchez, 2013), indicando de este tipo de hongos empelan el almidón como fuente de carbono y energía. Para el caso de los residuos de la yuca o de la papa, el seleccionar una o la otra, se tendría que analizar pensando en la cantidad, disponibilidad y fácil acceso para la obtención de estos residuos con los menores gastos logísticos posibles.

Con el análisis anterior, los incrementos proteicos seleccionados son de $166,29 \%$ y $171,05 \%$ para la papa y la yuca, respectivamente En la bibliografía pueden encontrarse datos de enriquecimiento proteico de diferentes residuos agroindustriales que han sido empleados como sustratos para FES. Por ejemplo, el reporte Dhillon et al (2013) con un incremento del 500\% de proteína con Candida utilis y Pleurotus ostreatus en pulpa de manzana.

Otro trabajo donde se emplearon residuos de yuca como sustrato fue el realizado por Ruqayyah et al (2014) inoculándole el basidiomiceto Panus tigrinus, obteniendo un incremento proteico del 55,16\%.

Algunos ejemplos donde se cultivaron bacterias y levaduras para enriquecer RA, es el caso de Hsu et al (2013) que emplearon pastos forrajeros y Entrophospora y Bacillus, obteniendo un incremento de 13,9\%. Por su parte, Correia et al (2007) emplearon la levadura Saccharomyces cerevisiae sobre residuos de piña obteniendo un incremento proteico del $22 \%$.

Como ejemplos de enriquecimiento con hongos filamentosos aparecen reportados los casos de Alvarez et al (2010) que cultivaron sobre residuos de banano Aspergillus niger aumentando la proteína en un 9,56\%. Adicionalmente, Bustamante et al (2008) reportaron la producción de proteína utilizando bagazo de naranja como sustrato para el crecimiento del Aspergillus niger. La concentración de nitrógeno orgánico inicial de $0.7130 \%$ aumentó a los 7 días a $1.18 \%$, a los 14 días a $2.05 \%$, a los 21 días a $2.49 \%$, alcanzando a los 28 días un valor de $2.89 \%$. Con base en estos resultados, se observó que la proteína aumenta desde $4.45 \%$ hasta $18.06 \%$, existiendo un incremento del $30.5 \%$ en 28 días de crecimiento del Aspergillus niger sobre el bagazo de naranja.

Una de las ventajas de emplear microorganismos para enriquecer RA es que en la mayoría de los casos no se hace necesario emplear gran cantidad de operaciones unitarias para conservar la transformación obtenida y los productos pueden emplearse directamente para la alimentación animal. De otro lado, estos procesos pueden ser rentables a gran escala debido a que la infraestructura de la FES es relativamente económica (Rupert, 1995); (Zapata \& Navas, 2006); (Padey, et al., 2008); (Mitchell, et al., 2006). Ejemplos de lo anterior son la Saccharina y el Bagarip: la Saccharina es un producto obtenido por fermentación solida de los tallos de caña de azúcar desprovistos de las hojas, de acuerdo con la tecnología desarrollada por el ICA -Cuba. Se reportan contenidos 
proteicos hasta del $13 \%$ en base seca y su biotransformación es debida a levaduras nativas del género Candida y Saccharomyses (Vivas y Carvajal, 2004); (Caridad, et al., 2007). Por su parte el Bagarip es una patente cubana, que emplea como sustrato RA procedentes de la industria de la caña, con un enriquecimiento hasta del 11\% (Brea, et al., 2014).

Con referencia a trabajos realizados con Paecilomyces variotti para la producción de proteína, se pueden reportar los trabajos realizados en hemicelulosa extraída de eucalipto, para un proceso de optimización obtuvo una concentración de proteína de $12.06 \mathrm{~g} / 1$ (Almeida, et al., 2003). Por su parte Steem (2014) empleó residuos de trigo obteniendo rendimientos de biomasas de 8 a $10 \mathrm{~g} / \mathrm{l}$ con un contenido aproximado de $50 \%$ de proteína. Los valores anteriores son inferiores a los obtenidos en este trabajo, en los cuales se obtuvieron concentraciones de proteína de 20,59 g/L y 25,05 g/l para la papa y la yuca, respectivamente. Aparte de la una mayor eficacia del microorganismo, una de las posibles explicaciones de las diferencias en los contenidos proteicos puede ser el proceso de extracción de proteína previo a la medición que se realizó en este trabajo. En la mayoría de los trabajos el contenido de proteína se cuantifica con el sustrato, razón por la cual la concentración o enriquecimiento es sustancialmente inferior al obtenido aquí.

\section{Conclusiones}

La papa y la yuca son alimentos energéticos con bajo contenido proteico y sus residuos o rechazos son un buen sustrato para el cultivo de microorganismos generadores de proteína microbiana o PUC. Las mejores condiciones de acuerdo a los resultados obtenidos fueron de humedad del $30 \%$, con fuente de nitrógeno de sulfato de amonio $(10 \mathrm{~g} /$ L) en un tiempo de 24 días. Se lograron obtener concentraciones de proteína de 166,29 \% y 171,05 $\%$ para la papa y la yuca, respectivamente.

\section{Referencias bibliográficas}

Aggelopoulos, T., Katsieris., Bekatorou, A., Pandey, A., Banat, I. M., Koutinas, A. A., 2014. Solid state fermentation of food waste mixtures for single cell protein, aroma volatiles and fat production. Science Direct. Food Chemistry. 145, p 710-716. https:// doi.org/10.1016/j.foodchem.2013.07.105
Aguilar-Navarro, B., Camacho-Pozo, M., \& Serrat-Díaz, M. de J., 2014. Enriquecimiento proteico de residuales agroindustriales mediante fermentación sólida con el hongo filamentoso Aspergillus niger. Revsita Cubana de Química, 26(1), 17-25. Consultado. http://search.ebscohost.com/login.aspx?direct= true $\& \mathrm{db}=$ fua $\& A N=103359609 \&$ lang $=$ es \&site $=$ ehost-live

Almeida, J. B., De Mancilha, I. M., Vannetti, M. C. D., \& Teixeira, M., 1995. Microbial protein production by Paecilomyces variotii cultivated in eucalyptus hemicellulosic hydrolyzate. Bioresource Technology, 52, 197-200. http://doi.org/10.1016/0960-8524(95) 00029-E. https://doi.org/10.1016/0960-8524(95) 00029-E

Almeida, J., Lima, U., Taqueda, M., Guaragna, F., 2003. Use of response surface methodology for selection of nutrient levels for culturing Paecilomyces variotii in eucalyptus hemicellulosic hydrolyzate. Bioresourse Technology. Volume 87, Issue 1, p 45-50. https:// doi.org/10.1016/S0960-8524(02)00199-2

Altaf, M., Naveena, B. J., Venkateshwar, M., Kumar, E. V., \& Reddy, G. 2006. Single step fermentation of starch to L $(+)$ lactic acid by Lactobacillus amylophilus GV6 in SSF using inexpensive nitrogen sources to replace peptone and yeast extract Optimization by RSM. Process Biochemistry, p 465472. Consultado. http://doi.org/10.1016/j.procbio. 2005.07.011

Alvarez, M. Larrea, P. Paredes, M., 2010. Fermentación sólida del banano de rechazo utilizando Aspergillus niger para alimento animal. Ambato: Universidad Técnica.

Ardestani, F., Alishahi, F., 2015. Optimization of Single Cell Protein Production by Aspergillus niger Using Taguchi Approach. Journal of Food Biosciences and Technology, 5(2):73-79.

Azam, S., Khan, Z., Ahmad, B., Khan, I., \& Ali, J. 2014. Production of Single Cell Protein from Orange Peels Using Aspergillus niger and Saccharomyces cerevisiae Pakistan Council of Scientific and Industrial Research Laboratories Complex, 9(1), 14-18. http://doi.org/10.5829/ idosi.gjbb.2014.9.1.82314

Badui, S., 2006. Química de los Alimentos (Cuarta ed.). Pearson. Ciudad de México. México, pp. 209-236 
Biocyclopedia. 2012. Substrates Used For Production of SCP - Single Cell Protein (SCP) \&amp; Mycoprotein. In Biocyclopedia. Consultado. http:// www.eplantscience.com/index/biotechnology/ microbial_biotechnology/single_cell_protein scp_and_mycoprotein/biotech_scp_substrates_ used_for_production.php

Brea, O., Ortiz, A., Elías, A., Herrera, F., Motta, W., 2014. Utilización de la harina de frutos del árbol del pan (Artocarpus altilis), fermentada en estado sólido, en dietas destinadas a cerdos en preceba. Revista Cubana de Ciencia Agrícola, 48(4):391-398

Bustamante, Z., Galindo, E., Huanca, M., Ballesteros, F., 2008. Obtención de bioproteina a partir de bagazo de naranja (Citrus sinensis) con Aspergillus niger. Programa Fármacos, Alimentos y Cosméticos, (PROFAC), Facultad de Bioquímica y Farmacia, Universidad Mayor de San Simón.

Caridad, M., Ricardo, J., Ramos L. 2007. Fermentación en estado sólido (i). Producción de alimento animal, Tecnología Química vol. xxvii, no. 3.

Chacón, A., 2004. Perspectivas actuales de la proteína unicelular en la agricultura y la industria, Agronomía mesoamericana. 15(1):93-106

Correia, R., Magalhaes, M., Macedo, G., 2007, Protein enrichment of pineapple waste with Saccharomyces cerevisiae by solid state bioprocessing, Jorunal of Scientific \& Industrial Research. March, 66:259- 262.

Dhillon, S., Kaur, S., Brar, S., 2013. Perspective of apple processing wastes as low-cost substrates for bioproduction of high value products: A review. Renewable and Sustainable Energy Reviews, 27, p 789-805. https://doi.org/10.1016/j.rser.2013. 06.046

FINAGRO., 2014. Informe estadístico de agricultura nacional por cultivos. Consultado el 21 de enero de 2016. http://www.finagro.com.co/html/i_portals/ index.php?p_origin=internal\&p_name $=$ content\&p_id $=\mathrm{MI}-$ $197 \&$ p_options $=\#$ COLOMBIA

Fontes, P., Gomide, L., Neuza., Costa, N., Peternelli, L., Fontes, E., Ramos, E, 2015. Chemical composition and protein quality of mortadella formulated with carbon monoxide-treated porcine blood, LWT - Food Science and Technology, Volume 64, Issue 2, December, p 926-931. https://doi.org/ 10.1016/j.lwt.2015.07.004

Hoover, R. 2002. Effect of heat-moisture treatment on the structure and physicochemical properties of tuber and root starches, Carboh. Polym.: 49(4), p 425-437. https://doi.org/10.1016/S0144-8617(01) 00354-X

Hsu, P., Liu, C., Liu, L., Chang, C., Yang, S., 2013, Protein enrichment and digestion improvement of napiergrass and pangolagrass with solid-state fermentation, Journal of Microbiology, Immunology and Infection, 46(3):171-179. https://doi.org/ 10.1016/j.jmii.2012.04.001

Hu, C., Liu, L, Yang, S., 2013. Protein enrichment, cellulase production and in vitro digestion improvement of pangolagrass with solid state fermentation. Journal of Microbiology, Immunology and Infection, Volume February, 45(1):7-14.

Ibrahim, R. M., 2009. Production of single cell protein through fermentation of a perennial grass grown on saline lands with Cellulomonas biazotea, National Institute for Biotechnology and Genetic Engineering, P.O. Box 577, Faisalabad, Pakistan.

Kurcz, A., B?a?ejak, S., Kot, A. M., Bzducha-Wróbel, A., \& Kieliszek, M. (2016). Application of Industrial Wastes for the Production of Microbial Single-Cell Protein by Fodder Yeast Candida utilis. Waste and Biomass Valorization, 8(37):1-8. https://doi.org/ 10.1007/s12649-016-9782-Z

Madeira, J. V., Macedo, J. A., Macedo, G. A., 2011. Detoxification of castor bean residues and the simultaneous production of tannase and phytase by solidstate fermentation using Paecilomyces variotii. Science Direct. Bioresource Technology. 102:7343-7348.

Merck., 2010. Potato Dextrose Agar, Microbiology Manual, 1.10130, Darmstadt, Germany 12th Edition, pp. 389-390.

Mitchell, D. A., Von Meien, O. F., Krieger, N., Dalsenter, F. D. H., 2004. A review of recent developments in modeling of microbial growth kinetics and intraparticle phenomena in solid-state fermentation. Biochemical Engineering Journal, 17(1):15-26. https://doi.org/10.1016/S1369703X(03)00120-7 
Nasseri, A. T., Rasoul-Ami, S., Morowvat, M. H., Ghasemi, Y., 2011. Single Cell Protein: Production and Process. American Journal of Food Technology. https://doi.org/10.3923/ajft.2011.103.116

Orlandoni, G., 1997. Modelos de crecimiento de poblaciones bilógicas: Un enfoque de dinámica de sistemas. Economía, XXII (23):115-146.

Oviedo, J. Casas, A., Valencia, J., Zapata, J., 2014. Análisis de la Medición de la Biomasa en Fermentación en Estado Sólido empleando el Modelo Logístico y Redes Neuronales. Información Tecnológica. 25(4):141-152. https://doi.org/10.4067/S071807642014000400016

Padey, A. Soccol, C. Larroche, C., 2008. Current Developments in Solid-state Fermentations. New Delhi: Asiatech Publishers, INC (Springer) pp. 4-8.

Peleg, M., Corradini, M. G., Normand, M. D. (2007). The logistic (Verhulst) model for sigmoid microbial growth curves revisited. Food Research International, 40(7):808-818. https://doi.org/10.1016/j.foodres. 2007.01.012

Pereira, A. D., Gomide, L. A. M., Cecon, P. R., Fontes, E. A. F., Fontes, P. R., Ramos, E. M., Vidigal, J. G., 2014. Evaluation of mortadella formulated with carbon monoxide-treated porcine blood. Science Direct. Meat Science. 97, pp. 164-173. https:// doi.org/10.1016/j.meatsci.2014.01.017

Pereira, S. R., Ivanuša, Š., Luzeiro, J., Mateus, C., Serafim, L. S., \& Xavier, A. M. R. B. 2010. Single Cell Protein production by Paecilomyces variotii from Spent Sulphite Liquor. Journal of Biotechnology, 150. Consultado en noviembre dee 2014. http://doi.org/ 10.1016/j.jbiotec.2010.09.802

Phetteplace, H., Jarosz, M., Uctuck, D., Spolrleder, R., 2003. Animal Sciences - Colorado State University. Recuperado el 18 de Febrero de 2009, de Animal Sciences - Colorado State University. Consultado http://ansci.colostate.edu/documents/renut/2000/ hp00.htm

Primo, E., 1998. Química de los Alimentos. Síntesis, p. 108.

Quesada, S., 2007, Manual de experimentos de laboratorio para bioquímica, EUNED, Primera edición. p. 34 .
Quiñonez, J., Lecompte, A., 2007.- Modelos exponencial y logístico de la población en el suroeste de Puerto Rico. Revista de investigación en ciencias matemáticas, 1(3):63-78.

Rezende, M., Barbosa, A., Vasconcelos, A., Endo, A., 2002, Xylanase Production by Trichoderma harzianum rifai by Solid State Fermentation on Sugarcane Bagasse. Brazilian Journal of Micribiology, vol.33 no.1 São Paulo Jan. 2002.

Ruqayyah, T., Jamal, P., Alam, M., Mirghani, M., Jaswir, I., Ramli, N, 2014, Application of response surface methodology for protein enrichment of cassava peel as animal feed by the white-rot fungus Panus tigrinus M609RQY. Food Hydrocolloids, 15 December, 42(2):298-303.

Sanchez, G. A., 2013. Evaluación de la degradación del tamo de arroz por hongos celulíticos aislados de suelos de cultivo de arroz. Tesis o trabajo de investigación presentada como requisito parcial para optar al título de Magister en Ciencias - Microbiología. Universidad Nacional de Colombia, Instituto de Biotecnología, pp. 75-85.

Steen, A., 2014. Production of Single Cell Protein from Residual Streams from 2nd Generation Bioethanol Production. Master of Science Thesis within Biotechnology, Performed at SP Processum AB, Örnsköldsvik, Sweden, Spring 2014. p. 85. Consultado el 9 de julio de 2015.

Suman, G., Nupur, M., Anuradha, S., \& Pradeep, B. (2015). Single Cell Protein Production: A Review. Int.J.Curr.Microbiol.App.Sci, 4(9):251-262.

Tacon, A., 1989. FAO. Recuperado el 20 de Enero de 2014, de Nutrición y alimentación de peces y camarones cultivados. Manual de capacitación: http:/ /www.fao.org/docrep/field/003/ab492s/ AB492S09. htm

Ukaegbu-Obi, K. M., 2016. Single Cell Protein?: A Resort to Global Protein Challenge and Waste Management. J Microbiol Microb Technol, 1(1):1-5. https://doi.org/ 10.13188/2474-4530.1000006

Vivas, N., Carvajal, J., 2004. Saccharina rustica una Aplicación Biotecnológica para la Alimentación Animal. Revista Facultad de Ciencias Agropecuarias, 2(1):43-48. 
Wang, C., Li, Y., 2012. Fungal pretreatment of lignocellulosic biomass. Biotechnology Advances, 30(6):1447-1457. https://doi.org/10.1016/j. biotechadv.2012.03.003
Zapata, J. L., Navas, G., 2006. Manejo agronómico de la papa, Centro de Investigación la Selva, Corpoica, Antioquia. 